\title{
Participants' perceptions of groupwork in the management of cancer symptoms in older people
}

Caroline Belchamber ${ }^{1}$

\begin{abstract}
This paper explores groupwork within rehabilitative palliative care on three distressing cancer symptoms: pain, dyspnoea and fatigue. This was achieved through qualitative methodology using a phenomenological orientated psychological approach in a cohort with a median age of 66 years. Groupwork, which included: social, exercise and divertional therapy groups were seen as important components within rehabilitative palliative care. Through semi-structured interviews the participants' perceptions of their symptoms, beliefs and attitudes towards their groupwork within rehabilitative palliative care were explored. The relevance and benefits of the groupwork were then identified using quality of life markers established during data analysis. The main factors uncovered and shown to contribute to the groupwork were: environmental factors, mobilisation and normalisation. However more research is required to comprehend how different forms of groupwork can help reduce pain, dyspnoea and fatigue in older people with cancer.
\end{abstract}

Key words: Rehabilitation; cancer; oncology; palliative care; groupwork; specialist palliative day care unit; symptom management; physiotherapy

\section{Lecturer in Physiotherapy, Bournemouth University}

Address for correspondence: Bournemouth University, Royal London House R601, School of Health and Social Care, Christchurch Road, Bournemouth, BH1 3LT, UK, cbelchamber@bournemouth.ac.uk 


\section{Introduction}

There has been a world-wide increase in the ageing population and subsequently a rise in older people being diagnosed with cancer (Cleary $\&$ Carbone, 1997). The median age for people with advanced lung cancer in the UK being 64 years, renal cancer 61 years and prostate cancer 79 years, in a cohort of 1000 participants (Donnelly et al., 1995). By 2025 it has been predicted that the number of cancers diagnosed each year as a direct result of the ageing population will be an additional 100,000 (Cancer Research UK, 2008).

Cancer has been highlighted by the UK National Health Service (NHS), as being one of the specific areas that needs to be targeted due to a predicted rise of disability of two million over 65 requiring assistance with activities of daily living (ADL) by 2031 (NHS R\&D, 1999). The report also states that age discrimination occurs in the quality of service provision for older people with cancer in the UK and has put forward a number of recommendations for instance, research into the provision of cost-effective rehabilitation; development and implementation of best practice for the management of distressing symptoms and optimal management of service delivery with interventions that reduce or prevent disability as a research priority.

The NHS cancer plan (DOH, 2000) outlines ways forward for cancer services focusing on patient-centered care with the Liverpool Care Pathway (2007) promoting a multi-disciplinary team (MDT) approach that encompasses the physical, psychological and spiritual well-being of people with cancer. These important elements have been addressed in this study providing health care professionals with an in-sight into the needs of older people with cancer.

Older people with cancer experience multiple symptoms (Dalal et al., 2006). High levels of anxiety and distress are also known to be associated with these symptoms leading to poor symptom control (Gessler et al., 2008). This paper presents a literature review identifying that pain, dyspnoea and fatigue are often the cause or effect of other debilitating symptoms thus strengthening the concept of rehabilitative palliative care whilst verifying that symptoms should not be treated in isolation.

Palliative care has been defined as the active total care of people whose disease is not responsive to curative treatment. Control of 
pain, of other symptoms, and of psychological, social and spiritual problems is paramount. The goal of rehabilitative palliative care is therefore the achievement of the best quality of life for people with lifelimiting conditions including cancers and their families (WHO, 1990 in Pan et al., 2000). The management of cancer symptoms however is predominantly challenging (Ragan et al., 2003) and often conveyed in alignment with co-morbidity (CSP, 2002).

\section{Groupwork within rehabilitative palliative care}

Groupwork with older people is seen as a skill required by health care professionals within the rehabilitation process (Corey and Corey, 2002). Most palliative day care units positively encourage the active participation of older people with cancer in their rehabilitative palliative care programmes and increasing importance is being placed on groupwork, community services, networking and team relationships (Cohen and Fried, 2007).

In other areas of rehabilitation with older people, groupwork has been shown to be an important element of rehabilitation in improving functional capacity and ADL while decreasing dependence and disability (Williams, 1994). Groupwork encourages socialisation with people who have similar conditions and disabilities. The opportunity to socialise and relax is thought to have positive effects on psychological well-being and treatment compliance or adherence (Lord et al., 1993; Rogind et al., 1998). Compliance is believed to be affected by three main factors: the attitude of the patient to the treatment received, the relationship between the practitioner and patient and the effect of the environment (Terpstra et al., 1992). Groupwork encourages empathy from health care professionals, the opportunity for relaxation and a change in environment (Ahern et al., 1995). All these factors that are thought to improve treatment outcomes, especially in respect of individual perceptions.

This paper explores groupwork within rehabilitative palliative care at a specialist palliative day care unit to identify best practice for the management of distressing symptoms: pain, dyspnoea and fatigue using interventions that aim to reduce disability and increase individual quality of life. 


\section{Aim of research}

The aim of the study was to explore the participants' perception of the rehabilitative palliative care at a specialist palliative day care unit and consider how this may be improved. The following research questions were posed:

- What perceptions do people with cancers' have of their symptoms?

- How do people with cancer perceive the rehabilitation services they received?

- What attitudes or beliefs do people with cancer have about the rehabilitation they have received?

\section{Literature review}

Research demonstrates that depression especially in older people has a negative influence on recovery (Glazer et al., 2002) with a higher incidence of anxiety and depression in older people with cancer (Higginson, 1997). There is also compelling evidence linking fatigue and psychological distress (Stone et al., 2000) with levels of fatigue, levels of pain (Hann et al., 2000), dyspnoea (Disalvo et al., 2008) and emotional upset (Helleberg and Sjogren, 2002). Research demonstrates that $25-40 \%$ of older people with cancer at a nursing home reported pain on a daily basis, which was inversely related to their age (Bernabei et al., 1998). Pain in people with cancer over 60 was also twice that of younger people with $33 \%$ of older people who had metastatic disease reporting an adverse effect on their ADL (Sheehand \& Forman, 1997).

With disease progression and increasing age, dyspnoea becomes more significant as lung volumes are reduced by up to a quarter of that of a younger person (Ahmedzai, 1997) with a consequential effect on lung capacity. This can be compounded by cancer with $41 \%$ of people with palliative care needs requiring management of dyspnoea (Curtis et al., 1991). Dyspnoea is a distressing symptom as breathing equates to life and therefore losing the capability to breathe has its clear consequence, imminent death (O’Driscoll et al., 1999).

Fatigue experienced by people with cancer is one of the most significant untreated symptoms today (Gregory, 2001) and is known 
to increase with age (Cleary \& Carbone, 1997). Collectively fatigue in people with cancer has cognitive, psychological and physiological causes (Gregory, 2001) having a negative impact on the person's ability to carry out ADL (Rhodes et al., 1988) with a reduction in quality of life (Stromborg \& Wright, 1994).

A study by Shaw and Wilkinson (1996) demonstrated that diversional therapy groupwork was an effective therapy for people with cancer, as it provided a sense of purpose - a factor thought to be essential for the overall wellbeing and self-identity of the person (Frampton, 1986). Some people with cancer in the group also experienced 'transcendence', where they could remove themselves mentally from their illness. In addition Spiegel et al. (1981) showed that people with cancer who received group therapy had a statistically significant reduction $(p<0.01)$ in pain sensation, pain suffering and fatigue levels.

Syrjala et al. (1995) compared four therapies: usual treatment; usual treatment with therapist support; usual treatment and group relaxation / imagery training; and usual treatment and group sessions of cognitive behaviour coping skills including relaxation/imagery. People with cancer reported less pain in the groups receiving the relaxation/imagery and the package of skills than those receiving the other interventions $(p<0.01)$. Fleming (1985) investigated relaxation therapy in a palliative day care unit and indicated that $38 \%$ of the 58 people with cancer pain had a reduction in their pain post relaxation therapy.

Corner et al. (1996) observed the non-pharmacological approach for dyspnoea in lung cancer, which involved groupwork using breathing retraining, exercises, counselling, relaxation and teaching of coping and adaptation strategies. Results demonstrated a median improvement in breathlessness at worst of 35\% ( $p=0.02)$; an improvement in distress caused by breathlessness of $53 \%(p=0.02)$; and an improvement in functional capacity of $17 \%(p=0.03)$. Hately et al. (2001) validated these results with significant improvements made in breathlessness at worst $(p<0.001)$, an improvement in distress caused by breathlessness $(p<0.004)$ and $100 \%$ satisfaction with information, explanation and time given.

Mock et al. (1997) investigated the effect of group exercises on people with cancer and observed a significant reduction in fatigue levels in those who exercised $(n=22)$ compared with the control group who received usual care $(n=24)$. 
Evidence suggests that older people with cancer have a higher incidence of psychological distress related to fatigue, which is seen as the overriding factor in this population having adverse effects on levels of pain and dyspnoea. There is some indication that groupwork such as diversional therapy may be a useful therapeutic tool in reducing these symptoms. Group therapy was also seen to have positive effects on pain and fatigue levels along with exercise and relaxation. Groupwork using a non-pharmacological approach also demonstrated positive results in the treatment of dyspnoea. The groupwork described in this study within the rehabilitative palliative care was therefore structured around the evidence presented in order to explore the effect of treating cancer symptoms in older people in a holistic manner.

\section{Method}

Research in palliative care should encompass the physical, psychological and emotional elements of the persons' experience (Field et al., 2001). A qualitative methodology was therefore chosen as it enables people to explore and discuss feelings associated with their illness, people are then able to 'make sense' of their experience while at the same time providing the researcher with invaluable information essential to acquire professional understanding of the phenomenon being explored.

A phenomenological orientated psychological approach was used as it aims to answer two related questions:

- 'What is the phenomenon that is experienced and lived?'

- 'How does it show itself?'

Through individual and unique reflection these questions are answered in a variety of ways (Vale and King, 1978) enabling the researcher to raise health care professionals' knowledge and perception of groupwork within rehabilitative palliative care.

\section{Data collection}

Colaizzi's (1978) methodology was selected for its structure and format, which followed a logical step-by-step procedure placing any 
pre-conceptions in brackets which helped to guide the researcher. Semistructured interviews were applied so that key issues could be explored in-depth. The addition of an agenda meant that there was consistency to the raw data providing a base for the initial stages of data analysis. Formulating questions around key issues, which had been identified in the literature review, as well as focusing upon the aims and objectives of the research established the agenda.

A 'simplified' model of research was chosen as the research framework, which included a 'pre-empirical stage' and an 'empirical stage' (Punch, 2000). This simplified model of research stresses: framing the research in terms of research questions, determining what data are necessary to answer those questions, designing research to collect and analyse those data, using the data (and the results of the data analysis) to answer the questions. In addition, Creswell's (1998) data collection cycle (figure 1) was applied.

An estimated sample size was made based on the concept of range by assessing the number of interviews that may be required to obtain a 'representative' view of the phenomenon being researched by theoretical

Figure 1

Data collection cycle (after Creswell (1998, p.110))

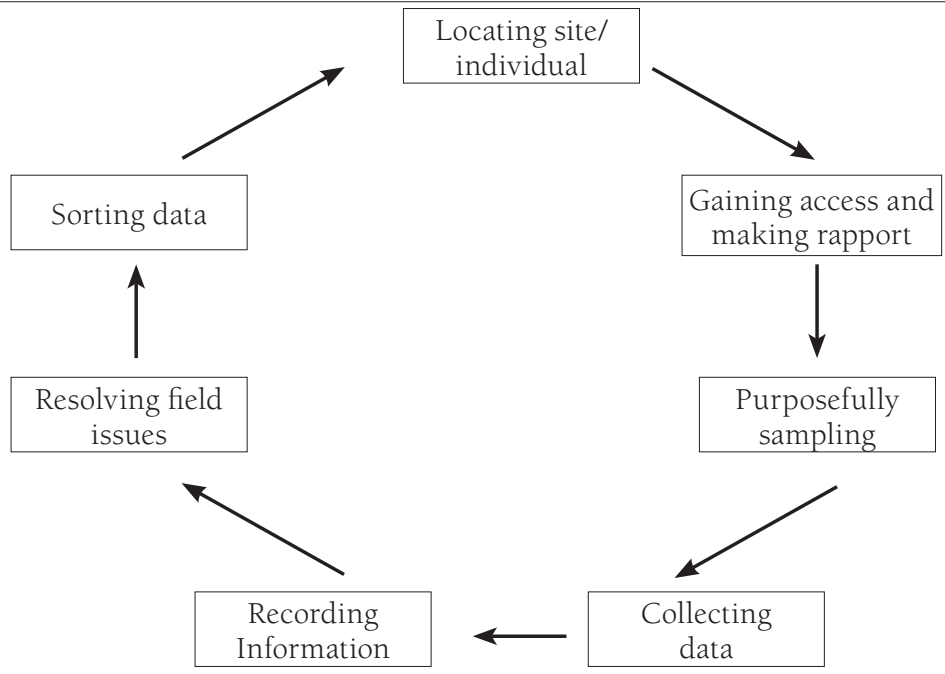


saturation. It was felt that eight participants would achieve this goal, although after five interviews saturation point would probably be accomplished. The nature of the sample in question also had to be taken into account. Any previous research using this participant group had experienced high drop out levels due to deterioration in health or death. Furthermore, the referral system at the specialist palliative day care unit meant that participants would not commence their two months research period at the same time and with this participant group, time is of the essence.

\section{Population characteristics}

This research involved people who were experiencing one of the three main symptoms of cancer: pain, dyspnoea or fatigue so that the effectiveness of groupwork within rehabilitative palliative care on these symptoms could be explored. Out of the eight participants four were experiencing pain, four were experiencing dyspnoea and seven were experiencing fatigue. Prior to the research, three participants had undergone surgery, radiotherapy and chemotherapy. One had undergone surgery followed by radiotherapy and three had undergone surgery followed by chemotherapy with just one participant having had surgery in isolation (see table 1).

Table 1

Sample characteristics by participant

\begin{tabular}{|c|c|c|c|c|c|}
\hline & Primary & Bone & Liver & Lung & \begin{tabular}{|l|} 
Lymph \\
nodes
\end{tabular} \\
\hline No. 1 & $\begin{array}{l}\text { Right breast cancer } \\
\text { (recurrence) }\end{array}$ & $\begin{array}{l}\text { Y (spine and right } \\
\text { arm) }\end{array}$ & - & - & Y (axilla) \\
\hline No. 2 & Bilateral breast cancer & - & $\mathrm{Y}$ & $\mathrm{Y}$ & - \\
\hline No. 3 & Renal cell carcinoma & - & - & $\mathrm{Y}$ & - \\
\hline No. 4 & $\begin{array}{l}\text { Cancer of the } \\
\text { oesophagus }\end{array}$ & - & - & - & - \\
\hline No. 5 & Colon cancer & - & $\mathrm{Y}$ & Y & \begin{tabular}{|l} 
Y \\
(abdomen) \\
\end{tabular} \\
\hline No. 6 & $\begin{array}{l}\text { Right breast cancer } \\
\text { (recurrence) }\end{array}$ & $\begin{array}{l}\text { Y (arms, hips, } \\
\text { spine and neck) }\end{array}$ & - & - & - \\
\hline No. 7 & Ca prostate & - & - & $\mathrm{Y}$ & - \\
\hline No. 8 & Unknown primary & - & $\mathrm{Y}$ & - & - \\
\hline
\end{tabular}


A purposeful sample group was selected to obtain maximum variation to allow the phenomenon in question to be analysed. Inclusion/ exclusion criteria were used to select a matched sample and to make sure that any cancer treatments such as radiotherapy or chemotherapy that would have had an effect on the person's experience of fatigue had been completed (see table 2). Haemoglobin levels were also assessed to make sure the fatigue was not related to anaemia or other medical conditions. It was also necessary to ensure that participants would be able to comprehend what was expected of them in the research and be able to tolerate a one-hour interview.

In total, 22 people fitting the inclusion/exclusion criteria were referred to the research. Five of the total referred declined as they felt it would be too much, too tiring, or the interview too exhausting. Two

Table 2

Inclusion/exclusion criteria

\begin{tabular}{|l|l|}
\hline Inclusion criteria & Exclusion criteria \\
\hline $\begin{array}{l}\text { The person must be capable of articulating } \\
\text { his/her conscious experiences (Creswel,1 } \\
\text { 1998) }\end{array}$ & $\begin{array}{l}\text { People who would require further } \\
\text { palliative chemotherapy or palliative } \\
\text { radiotherapy }\end{array}$ \\
\hline $\begin{array}{l}\text { The person must be experiencing one or } \\
\text { more of the following symptoms; pain, } \\
\text { dyspnoea or fatigue }\end{array}$ & $\begin{array}{l}\text { People with underlying pathologies such } \\
\text { as cardio-vascular disease }\end{array}$ \\
\hline $\begin{array}{l}\text { The person must have a diagnosis of } \\
\text { cancer and have completed either their } \\
\text { palliative chemotherapy, palliative } \\
\text { radiotherapy or in some cases both at } \\
\text { least four weeks prior to commencing } \\
\text { the research }\end{array}$ & $\begin{array}{l}\text { People with a history of cardio-vascular } \\
\text { accidents }\end{array}$ \\
\hline $\begin{array}{l}\text { Haemoglobin must not be below } \\
\text { 10mmHg }\end{array}$ & $\begin{array}{l}\text { People with a history of myocardial } \\
\text { infarctions }\end{array}$ \\
\hline $\begin{array}{l}\text { GP must agree to carry out a blood test } \\
\text { prior to being accepted onto the study }\end{array}$ & $\begin{array}{l}\text { People with a haemoglobin level below } \\
10 m m H g\end{array}$ \\
\hline $\begin{array}{l}\text { The person must be fit enough to } \\
\text { participate in the rehabilitative palliative } \\
\text { care over a two month period. }\end{array}$ & $\begin{array}{l}\text { People who aren't fit enough to participate } \\
\text { in the rehabilitative palliative care over a } \\
\text { two month period. }\end{array}$ \\
\hline
\end{tabular}


deteriorated in health and were admitted to hospital and seven died. This research was therefore based upon eight participants who were able to complete the full research period.

\section{Ethical issues}

There are many ethical issues surrounding palliative care and this is perhaps why very little research has been done in this specialist and important area. Indeed, research in palliative care is often met with resistance due to the vulnerability of the people involved. In aiming to protect this group of people we might be denying them the right to participate in research even if their participation may well benefit people in the future (NCHSPC, 1994).

In this research ethical approval was sought from the local ethics committee and access to sites was obtained from the researcher's employer. One-to-one interviews were carried out to explain the research to the potential participant. During this interview the person was asked whether they might volunteer to take part in the research. If the person volunteered, verbal consent had been provided protecting the rights of the research participant. Following verbal consent the researcher asked the participant for informed consent prior to the semistructured interview.

On receipt of research information each participant was asked to sign a consent form. 'Process consent' (McLeod, 1996) was then used to gain consent at each stage. This process continued to protect the participant's vulnerability and the interviewer from any misunderstandings by the participant. Pseudonyms were also applied so that participants could not be identified and an Identification code was issued on individual interview agenda forms.

Confidentiality was maintained throughout the research. Only those involved in the research had access to the raw data and they were required to sign a confidentiality form. Information was stored on computer files, which were password protected and raw data was kept in a locked filing cabinet assigned for the research according to the requirements of the UK Data Protection Act 1998. A further procedure agreement was drawn up for working practice both at the specialist palliative day care unit and off the premises at the researcher's own 
home. Confidentiality of the research environment was also protected and is referred to as the specialist palliative day care unit.

The researcher was a member of the multi-disciplinary team, which poses both an ethical as well as a bias issue. The researcher was acutely aware of this and acknowledged that the participants might 'reply as they think they should' which could potentially affect the quality of the data collected. In this situation the researcher could have influenced both the asking of the questions and also the interpretation of the answers. To overcome this, the researcher remained as neutral as possible during the construction of the interview agenda and also explained to the participants that they should not feel uncomfortable about expressing any critical views regarding the physiotherapy input during the rehabilitative palliative care, as it would not affect their future care. Even though these ethical and bias issues were present, it is important to remember that unlike quantitative research the subjectivity of the researcher can become a resource (Holloway, 1997)

\section{Data analysis}

Semi-structured interviews were recorded and transcribed wordfor-word and the raw data was placed in table format starting with a procedure known as 'horizontalisation' where the original transcriptions were reduced into significant statements. Following this procedure the significant statements were condensed further into formulated meanings and tabulated under key themes, which were then clustered together into common themes. To complete this data analysis a structural description was applied and an exhaustive description of the rehabilitative palliative care explained.

\section{Discussion of findings}

Participants described symptoms of pain, dyspnoea and fatigue in a three-dimensional manner including physical, emotional and spiritual elements. These elements had a strong correlation with the participants' perceptions of their physical symptoms and disabilities. The latter is clearly seen in the participants' description of their quality of life 
before the rehabilitative palliative care (see table 3) demonstrating a prevailing sense of loss and isolation. The latter had a negative effect on wellbeing, hope, self-esteem, role, social support, emotional support, energy, strength, mobility and control. Factors, which were seen to have a positive effect on the latter, included environmental factors, positive outlook, groupwork and normalisation, which confirms findings from Lord et al. (1993) and Rogind et al.'s (1998) studies.

\section{Pain}

Words such as terrifying, frightening and devastating were used to describe pain. This emotional element of pain impacted not only on the individual but also on close family members and friends with a consequent increase in anxiety and sense of isolation. Relaxation at the end of group exercise was perceived as having a positive effect on this emotional pain and so confirms Syrjala et al.'s (1995) findings while supporting Fleming's (1985) research that cancer pain can be relieved through relaxation. In addition, groupwork was seen to decrease both physical and emotional pain (table 3), validating Spiegel et al.'s (1981) research on group therapy.

\section{Dyspnoea}

Participants perceived that both the exercise and diversional therapy groupwork had a positive effect on their breathlessness giving them a sense of control. This led to an improvement in functional capacity and overall quality of life (see table 3) verifying Corner et al.'s (1996), Hately et al.'s (2001) and Williams' (1994) research findings.

\section{Fatigue}

Participants described fatigue as the overriding symptom that affected their quality of life and ability to carry out ADL, confirming Rhodes et al.'s (1988) findings that fatigue has a negative impact on an individual's ADL. Psychosocial issues also compounded the fatigue along with a loss of appetite, weight, strength and muscle atrophy due to malnourishment and reduced mobility. These findings corroborate Gregory's (2001) research that fatigue in people with cancer has cognitive, psychological 
Table 3

Formulated meanings of significant statements

Number Formulated meanings

Diversional therapy

1 Individuals found it interesting and were inspired by other people's efforts

2 It was seen to provide opportunities of being creative, challenging you to achieve and learn something new

3 Accomplishing the challenge provided the individual with a sense of worth and ability to succeed in other areas of their rehabilitation

\section{Group exercises}

1 Individuals found this a social event which they enjoyed as it was in a group

2 The group setting acted as an incentive for all participating

3 The exercises were found to be beneficial increasing mobility, and strength

$4 \quad$ The exercises helped to replace a sense of physical loss from the individual's past

5 Doing the exercises while sitting meant that whatever the individual's physical disability they were able to join in.

Pre-quality of life

$1 \quad$ Quality of life was poor due to a low mood and negative attitude

2 Negative thoughts led to low self esteem and a sense of abandonment

3 Quality of life was reduced due to physiological and psychological disabilities

Post-quality of life

$1 \quad$ Mobility increased with an improvement in health and reduction in pain

2 Reduction in negative emotions increased ability to do more, alleviating fatigue

3 Quality of life improved rapidly along with general condition thus positively affecting the individual's whole life

$4 \quad$ Attending the specialist palliative day care unit added to the individual's quality of life enabling them to achieve more

5 Being in control of the situation provided the individual with a sense of normality

6 Quality of life improved through positive attitudes of 'happiness,' 'fitness' and 'lack of worry' 
and physiological causes. The latter also substantiates Stone et al.'s (2000) findings that there is a parallel between levels of pain, dyspnoea, emotional upset and fatigue.

Group exercises were shown to decrease fatigue and so confirm Mock et al.'s (1997) findings while verifying Spiegel et al.'s (1981) research that groupwork has an important role in decreasing fatigue levels. However, the environment in which the groupwork was carried out in this research was also seen to have an effect on this finding (see table 3), which parallels Terpstra et al.'s (1992) findings.

\section{Environmental factors}

During rehabilitative palliative care the participant's perceptions of abandonment, anxiety and loss of control (see table 4) is altered through social contact, communication and group activities as well as the health care professional's acknowledgement of the participant's individuality and value through attentive listening and appropriate response nurturing unity and wholeness (see table 4). This sense of well-being is enhanced through a comforting, secure, stimulating and remedial environment encouraging motivation and compliance (see table 4) which corroborates both Terpstra et al.'s (1992) and Ahern et al.'s (1995) findings.

The social environment plays a vital role in any individual's life, and involves different groups of people such as family, peers, friends, neighbours, service agents and community members. The behaviour, culture, expectations, attitudes and religions all add to a person's environment (Bauer, 1989).

The nature of the social environment provided by the specialist palliative day care unit and the impact of working in groups (see table 3) has been shown through this research to meet the social needs of the individual which include peer recognition, peer respect, the need to belong to a group, the need for human relationships, the need for security and protection and the need for creative opportunities and recreation (Bauer, 1989).

\section{Positiveness}

Positive and negative attitudes were discussed at length by all 
Table 4:

Clusters of common themes

Numbers Common themes

$1 \quad$ Participant's negativeness

a. Negative feelings and attitudes arose from isolation producing a sense of abandonment

b. The sense of abandonment increased anxiety and stress levels ultimately leading to loss of control

$2 \quad$ Participant's positiveness

a. Positive feelings and attitudes were nurtured through contact with peers and health care professionals producing a sense of unity

b. The sense of unity was increased through group activities, communication, enquiry and the ability to express feelings producing a sense of wholeness

$4 \quad$ Environment's atmosphere

a. Participants perceived the atmosphere as comforting, secure, stimulating and remedial providing a sense of well-being

b. The sense of well-being increased motivation, compliance and a positive change in how the participant perceived their symptoms

$5 \quad$ Physiological symptoms

a. Participants perceived that the diversional therapy helped to take their mind off the dyspnoea

b. Participants perceived that group exercises were an incentive and helped to increase strength while diversional therapy provided an opportunity to accomplish something which increased self-esteem and the ability to succeed in other areas of their rehabilitation

participants and seemed to be a major quality of life indicator in their rehabilitation (see table 4). Changing from a negative attitude, to a positive attitude was perceived by the participant to be the key to their change in bodily health. The feeling of belonging to a group was also very strong and participants used words such as 'club' to describe it. This sense of belonging, however, brings with it dependence and one surprising comment was:

I would feel very jealous of the person who was following me and I know that I am very lucky to come here because I know there are a lot more people with cancer 
than there are people that come here in the area so I am very lucky to come here and I will feel jealous of the person who follows in my footsteps.

This demonstrates not only the attachment that people form with the specialist palliative day care unit but also the person's sense of ownership which Gibbon and Kenny (1993) believe is required for people to be committed to a programme of care, however this brings with it difficulties in discharging people.

\section{Normalisation process}

A normalisation process (see table 3) was observed in the groupwork where participants felt able to achieve more in their lives:

I come here and I've seen what other people can do in, never mind about, I'm not talking about the cancer side of it, I'm talking about ordinary people like me who sit down at the table. It's not so much the painting it's learning to do something different and think well, yeah I can do anything.

Shaw and Wilkinson (1996, p. 221) state, 'It is often said that people only feel themselves to be truly alive when stretching and testing themselves.' Diversional therapy offered this to the participants as they frequently described their craft activities as challenging. The normalisation process observed in the diversional therapy groupwork confirms the results of Shaw and Wilkinson's (1996) research and demonstrates that it plays a key role in the rehabilitative palliative care process.

The normalisation process was viewed as an acceptance of the diagnosis and disability, and the particular needs of that individual with the disability. It was seen to initiate the rehabilitative palliative care programme and could be considered the key element in determining the quality of the service (O'Brian, 1980).

\section{Groupwork}

Groupwork was seen as enjoyable, important and an encouragement to each other promoting greater perseverance as well as a sense of identity and unity. As one participant stated: 
I think doing it in a group is good because it is encouraging as you are spurring one another along if you like.

This comparison with others provided a source of inspiration and incentive to the participants especially in activities such as diversional therapy and group exercises. Diversional therapy not only provided the creative opportunities and recreation for the participants, but also met the participant's needs of belonging to a group which was echoed in the exercise group and described as social:

I suppose the physiotherapy is a treatment but it's more of a social event because everyone gets round in a circle.

Group exercises (see table 3) were seen as an incentive and helped to increase strength as well as replacing a sense of physical loss from the individual's past:

Well, being a sporty person that's the sort of thing that I miss.

The exercise group was also thought to contribute to the quality of mobility by strengthening muscles, while reducing 'stiffness' and encouraging more movement.

Participants achieved a lot of personal satisfaction from being involved in the diversional therapy groupwork (see table 3) as it presented opportunities and challenges. The act of accomplishing such tasks provided the individual with a sense of self-worth as well as the ability to succeed in other areas of their rehabilitation:

It gives us the opportunity of trying something new of trying something different, but eh perhaps after a while you realise you can do other things

This confirms Hockley's (1993) statement that diversional therapy can help people with cancer to become less withdrawn enabling them to think and do things 'outside of themselves'.

A correlation was noted between participation in the exercise and diversional therapy group in helping to improve participants' perception of fatigue and dyspnoea. This may well have been due to the distraction the diversional therapy offered to the participants taking their mind off their symptoms and psychologically providing them with skills 
to achieve more than they thought they physically could. With this renewed confidence and the increase in strength the participants' perception of their fatigue altered. One such comment about the diversional therapy indicates this effect on the participants' perception of their breathlessness:

It makes you forget everything else I mean I forget, I forget to be breathless.

Participants also referred to improvement in their mobility on numerous occasions and yet from a physical point of view the majority of the participants were independently mobile. Their perception of immobility was often associated with sitting at home watching television, which was frequently related to their fatigue levels or breathlessness, although one was due to physical pain. Interestingly, the actual action of preparing themselves and getting themselves out to attend the specialist palliative day care unit was seen as a great benefit and was perceived as being a contributory factor of improving their mobility status. Furthermore, the introduction of the rehabilitative palliative care to the participants, where both physical and mental abilities were stretched, may well aid sleeping patterns and therefore be helpful in reducing fatigue, as one participant stated:

I've noticed when I've been here I go home and sleep much better.

\section{Conclusion}

This research has provided an insight into some of the benefits of groupwork within rehabilitative palliative care in a specialist palliative day care unit. The participants' perceptions of their symptoms, beliefs and attitudes towards rehabilitative palliative care have been explored which has provided the researcher with the means to increase healthcare professionals' awareness and insight into types of groupwork for older people with cancer. However, further research is needed into groupwork where cancer is an issue as well as exploration of participants' attitude of gratefulness, which may have an impact on research findings. In this study groupwork was seen to play an important role in the management of dyspnoea, fatigue, mobility, environmental factors and the normalisation process increasing the persons ADL and quality of life. 


\section{References}

Ahern, M., Nicholls, E., Simionato, E., Clark, M. and Bond, M. (1995) Clinical and psychological effects of hydrotherapy in rheumatic diseases. Clinical Rehabilitation, 9, 204-212

Amedzai, S. (1997) Palliation of respiratory symptoms. in D. Doyle, G.W.C. Hanks, and N. MacDonald, N. (Eds.) Oxford Textbook of Palliative Medicine. Oxford: Oxford University Press (pp.349-378)

Bauer, D. (Ed.) (1989) Foundations of Physical Rehabilitation: A management approach Edinburgh: Churchill Livingstone

Bernabei, R., Gambassi, G., Lapane, K., Landi, F., Gatsonis, C., Dunlop, R., Lipsitz, L., Steel, K, and Mor, V. (1998) Management of pain in elderly patients with cancer. Journal of the American Medical Association, 279, 1877-1882

Cancer Research UK (2008) Cancer Research UK Statistical Information. Http:// info.cancerresearchuk.org/cancerstats/incidence/risk (accessed June 2008) Chartered Society of Physiotherapy (CSP) (2002) The Effectiveness of Physiotherapy in the Palliative Care of Older People available at www.csp.org.uk (accessed 2003)

Cleary, J. F., and Carbone, P.P. (1997) Palliative medicine in the elderly. Cancer, 80,1335-1347

Cohen, M. and Fried. G. (2007) Comparing relaxation training and cognitivebehavioural group therapy for women with breast cancer. Research on Social Work Practice, 17, 313-323

Colaizzi, P. F. (1978) Psychological research as the phenomenologist views it. in R. Vale, and M. King (Eds). Existential Phenomenological Alternatives for Psychology. New York: Oxford University Press (pp.48-71)

Corey, M. S. and Corey, G. (2002) Groups: Process and practice. (6th ed.) Pacific Grove, CA: Brooks / Cole

Corner, J., Plant, H., A'Hern, R., and Bailey, C. (1996) Non-pharmacological intervention for breathlessness in lung cancer. Palliative Medicine, 10, 299-305

Creswell, J.S. (Ed.) (1998) Qualitative Inquiry and Research Design: Choosing among the five traditions. Thousand Oaks CA: Sage

Curtis, E.B., Krech, R., Walsh, T D. (1991) Common symptoms in patients with advance cancer. Journal of Palliative Care, 7, 25-29

Dalal, S., Fabbro, E.D., and Bruera, E. (2006) Symptom control in palliative care - part 1: oncology as a paradigmatic example. Journal of Palliative Medicine. 9, 2, 391-408

Data Protection Act 1998 available at http://www.opsi.gov.uk/acts/ 
acts1998/19980029.htm (accessed December 2008)

Department of Health (DOH). (2000) National Health Service (NHS) Cancer Plan. London: HMSO

Disalvo, W.M., Joyce, M.M., Tyson, L.B., Culkin, A.E., and Mackay, K. (2008) Putting evidence into practice: evidence-based interventions for cancerrelated dyspnea. Oncology nursing, 12, 2, 341-352

Donnelly, S., Walsh, D., and Rybicki, L. (1995) The symptoms of advanced cancer: ID of clinical and research priorities by assessment of prevalence and severity. Journal of Palliative Care, 11, 27-32

Field, D., Clark, D., Corner, J. and Davis, C. (Eds.) (2001) Facing Death: Researching palliative care. Buckingham: Open University Press

Fleming, U. (1985) Relaxation therapy for far-advanced cancer. Practitioner, 299, 471-475

Frampton, D. (1986) Restoring creativity to the dying patient. British Medical Journal, 293, 6562, 1593-1595

Gessler, S., Low, J., Daniells, E., Williams, R., Brough, V., Tookman, A. and Jones, L., (2008) Screening for distress in cancer patients: is the distress thermometer a valid measure in the UK and does it measure change over time? A prospective validation study. Psycho-Oncology, 17, 6, 538-547

Gibbon, B. and Kenny, M. (1993) Nurses' attitudes to patient activation. Nursing Standard, 8, 8, 35-39

Glazer, K.M. Emery, C.F. Frid, D.J., and Banyasz, R.E. (2002) Psychological predictors of adherence and outcomes among patients in cardiac rehabilitation. Journal of Cardiopulmonary Rehabilitation, 22, 40-46

Gregory, A.C. (2001) Fatigue in cancer. British Medical Journal, 322, 1560

Hann, D. M., Denniston, M. M. and Baker, F. (2000) Measurement of fatigue in cancer patients: Further validation of the Fatigue Symptom Inventory. Quality of Life Research, 9, 847-854

Hately, J., Scott, A., Laurence, V., Baker, R., and Thomas, P. (2001) A PalliativeCare Approach for Breathlessness in Cancer: A clinical evaluation. London: Help the Hospices

Hellegerg, C. and Sjogren, P. (2002) Self-assessment in cancer patients referred to palliative care. A study of feasibility and symptom epidemiology. Cancer $94,512-520$

Higginson, I. (1997) Palliative Care and Terminal Care: Health care needs assessment. Abingdon: Radcliffe Medical Press

Hockley, J. (1993) Rehabilitation in palliative care: Are we asking the impossible? Palliative Medicine, 1, 9-15 
Holloway, I. (Ed.) (1997) Basic Concepts for Qualitative Research. London: Blackwell Science

Liverpool Care Pathway (2007) Marie Currie Palliative Care Institute. Liverpool. http://www.endoflifecareforadults.nhs.uk/eolc/eolcpub.htm (accessed December 2008)

Lord, S., Mitchell. D., and Williams, P. (1993) Effect of water exercise on balance and related factors in older people. Australian Physiotherapy, 39, 217-222

McLeod, J. (1996) Qualitative approaches to research in counselling and psychotherapy: issues and challenges. British Journal of Guidance and Counselling, 24, 3, 309-316

Mock, V., Dow, K. H., Meares, C.J., Grimm, P.M., Dienemann, J.A., HaisfieldWolfe, M.E., Quitasol, W., Mitchell, S., Chakravarthy, A., and Gage, I. (1997) Effects of exercise on fatigue, physical functioning and emotional distress during radiation therapy for breast cancer. Oncology Nursing Forum, 24, 6, 991-1000

National Council for Hospice and Specialist Palliative Care Services (NCHSPCS) (1994) Research in palliative care: the pursuit of reliable knowledge. Occasional paper 5 London: NCHSPCS

National Health Service (NHS) research and development (RandD) (1999) Strategic Review of Ageing and Age-associated Disease and Disability. London: NHS RandD/DoH

O'Brien, J. (1980) The Principle of Normalisation: A foundation for effective services. Atlanta Georgia: Responsive Systems Associates

O'Driscoll, M., and Corner, J. and Bailey, C. (1999) The experience of breathlessness in lung cancer. European Journal of Cancer Care, 8, 37-43

Pan, C.X., Morrison, R.S., Ness, J., Fugh-Berman, A., and Leipzig, R.M. (2000) Complementary and alternative medicine in the management of pain, dyspnoea and nausea and vomiting near the end of life: A systematic review. Journal of Pain and Symptom Management, 20, 5, 374-386

Punch, K. F. (Ed.) (2000) Developing Effective Research Proposals. London: Sage Ragan, S.L., Wittenberg, E., and Hall, H.T. (2003) The communication of palliative care for the elderly cancer patient. Health Communication, 15, 2, 219-226

Rhodes, V.A., Watson, P.M., and Hanson, B.M. (1988) Patients' descriptions of the influence of tiredness and weakness on self-care abilities. Cancer Nursing, 11, 3, 186-194

Rogind, H., Bibow-Nielsen, B., Jensen, B., Moller, H., Frimodt-Moller, H., and Bliddal, H. (1998) The effects of a physical training programme on patients 
with osteoarthritis of the knees. Archives of physical medicine and rehabilitation, 79, 1421-1427

Shaw, R., and Wilkinson, S. (1996) Building pyramids: Palliative care patients' perceptions of making art. Therapy and Rehabilitation, 2, 4, 217-221

Sheehan, D.C. and Forman, W.B. (1997) Symptomatic management of the older person with cancer. Clinics in Geriatric Medicine, 13, 203-219

Spiegel, D., Bloom, J., and Yalom, I. (1981) Group support for patients with metastatic cancer: A randomised prospective outcome study. Archives of General Psychiatry, 38, 527-533.

Stone, P., Richards, M., A'Hern, R., and Hardy, J. (2000) A study to investigate the prevalence, severity and correlates of fatigue among patients with cancer in comparison with a control group of volunteers without cancer. Annals of Oncology, 11, 561- 567

Stromborg, F.M. and Wright, P. (1994) Ambulatory cancer patients' perception of the physical and psychosocial changes in their lives since the diagnosis of cancer. Cancer Nursing, 7, 2, 117-130

Syrjala, K.I., Donaldson, G. W. ,and Davis, M.W. (1995) Relaxation and imagery and cognitive-behavioural training reduce pain during cancer treatment: A controlled clinical trial. Pain, 63, 189-198

Terpstra, S.J., de Witte, L.P., and Diederiks, J.P.M. (1992) Compliance of patients with an exercise program for rheumatoid arthiritis. Physiotherapy Canada, $44,37-41$

Vale, R. and King, M. (1978) Existential Phenomenological Alternatives for Psychology. New York: Oxford University Press

Williams, M. A. (1994) Exercise Testing and Training in Elderly Cardiac Patients. Current issues in cardiac rehabilitation. Monograph no. 1. Champaign, IL: Human Kinetics Publication

World Health Organisation (WHO) (1990) Cancer Pain Relief and Palliative Care: Report of a WHO expert committee Technical Report Series: 804 Geneva: WHO 